\title{
Surgery for fragility hip fracture-streamlining the process
}

\author{
F. Leung $\cdot$ M. Blauth $\cdot$ S. Bavonratanavech
}

Received: 18 August 2010 / Accepted: 31 August 2010

(C) The Author(s) 2010. This article is published with open access at Springerlink.com

Throughout the past few decades, demographics are changing swiftly throughout the world. In the United States, Japan, China, and many parts of Europe, life expectancy has risen to well above 70 years [1]. As a result, there is an expected increase in the number of hip fractures in the world and an increasing demand for treatment of fragility fractures [2]. Moreover, with an active lifestyle that many older patients used to enjoy, there is a bigger demand for a prompt and effective healing of the fractures and an early return to premorbid level.

Fragility hip fracture is the most severe kind of fracture that is caused by osteoporosis. Hip fracture patients have a high mortality rate of up to $30 \%$ during the first year after their hip fracture [3]. Moreover, their ambulation and quality of life are significantly affected by the fracture as only $50 \%$ regained their prefracture functional status in terms of ambulatory ability and the need for walking aids [4]. The fundamental goal of management of these patients is to give them a painless and functional limb that allows early weight bearing. As a result, these patients will most likely need surgical treatment and afterwards need a variable period of rehabilitation either in the convalescent

F. Leung $(\bowtie)$

Department of Orthopaedics and Traumatology,

Queen Mary Hospital and The University of Hong Kong,

Hong Kong, China

e-mail: klleunga@hkucc.hku.hk

\section{Blauth}

Department of Trauma Surgery and Sports Medicine,

Medical University of Innsbruck,

Innsbruck, Austria

S. Bavonratanavech

Department of Orthopaedics, Bumrungrad Hospital,

Bangkok, Thailand hospital or in the community. This constitutes a significant health problem and a major burden to the society.

In the past few decades, there have been advancements in the surgical implants in the treatment of fragility fractures. Modern methods of hip arthroplasty can provide a painless and highly functional outcome in the active elderly patients having femoral neck fractures [5]. The sliding hip screw and intramedullary nailing using the same principles have been the standard treatment of intertrochanteric fractures [6]. Recently, an improvement in the fixation of the osteoporotic femoral head in the form of a helical blade has shed new light in related implant design [7]. In addition to devising new implants and fixation materials, recommendations on the surgical technique and implant position such as the tip-apex distance of the lag screw position have also been established to help surgeons deliver the best surgery to their patients [8]. From a logical point of view, orthopedic surgeons hypothesize that by having the latest implant and performing a successful surgery, they can have an immediate impact in the outcome of these patients. This goal has not been fully realized.

Surgeons gradually realize that other factors may have equally significant influences on patient outcome. Instead of concentrating solely on pursuing excellence in surgical techniques to fix a fracture more stably, should we also put a big effort to improve the performance of existing medical care for such patients? Are these hip fracture surgeries done promptly without delay as in the case of other long bone fractures? Are the surgeries left in the hands of residents who are relatively inexperienced? How about the other medical illnesses of these patients that may alter significantly the eventual outcome? In many parts of the world, a system of orthopedic trauma service and the organization of the hospital that values prompt treatment of these patients are lacking. Hence, the orthopedic surgeon encounters 
obstacles in delivering a prompt and effective surgical treatment to these patients. There are two main aspects in accounting for such delays to surgery.

Hip fracture patients are typically in their $70 \mathrm{~s}-90 \mathrm{~s}$. Preexisting comorbidities are commonplace, and hence, many patients are not in the most optimal body conditions to undergo anesthesia and surgical procedures. To correct the underlying medical conditions will often need some time. To address this situation, an individual assessment is required upon hospital admission, and individualized therapy programs should be planned. This assessment must be completed as soon as possible to allow the patient's condition to be rapidly optimized for surgery. On the other hand, delaying the hip fracture surgery will predispose the patient to pulmonary, urinary, thromboembolic, and bed sore complications. Hence, there is often a dilemma faced by the health care workers as how much optimization is needed for hip fracture surgery. Therefore, an orthopedic surgeon sometimes stands on one's own, with little more than the basic medical knowledge, to cope with a system that is very unlikely to satisfy an ever growing number of patients.

In general, orthopedic surgeons cannot accept sole responsibility for all these very complex problems. Involving multidisciplinary members in the treatment is a clear direction. Geriatricians, cardiologists, and anesthetists all become stakeholders. Clinical pathways or geriatric fracture programs involving a team of health care professionals from different disciplines have been developed in some centers to ensure prompt and safe management of hip fracture patients. There have also been efforts in establishing a conjoint orthogeriatric service to provide a comprehensive care to these patients in a comanaged manner.

Besides comorbidities of the geriatric patients, there are problems related to the process or the system that delay surgery to these patients. Despite the increasing demand in the treatment of fragility hip fractures, hospital administration and government health organizations in much of the world still turn a blind eye to this trend. Scarce resources are not to be blamed. Better use of existing resources is clearly necessary. The availability of a dedicated operating theater for hip fracture surgery has been shown to be effective [9]. Recently, there have been also encouraging attempts to establish national guidelines for the management of elderly hip fractures, such as the SIGN guidelines [10] and the British Orthopaedic Association guidelines [11].

Monitoring of the process of management of these hip fracture patients by the government or health administration organizations will no doubt also play a significant role in ensuring early surgical treatment of these patients. One may argue that this is due to the Hawthorne effect whereby a short-lived increase in productivity is seen when the performance is being measured [12]. On the other hand, as long as early surgery does not conflict with their wellbeing, elderly hip fracture patients would clearly benefit from such clear directions.

Management of osteoporotic fractures has been a priority of the AO Foundation. The initial focus was on concept development of surgical techniques to enable better fixation in osteoporotic bone. What started as a strategic initiative in 2003 has become an integral part of AO's Clinical Priority Program 'Fracture Fixation in Osteoporotic Bone'. It provided an opportunity for orthopedic and traumatological experts to meet and work with specialists from internal medicine, anesthesiology, and radiology.

The aim of this supplement is to provide health care workers of all disciplines an update of the current opinions on how to better prepare their patients for surgery, and to show the different efforts to overcome the administrative, logistics, and organizational hindrance to a timely hip fracture surgery. In fact, the current concept of geriatric fracture care should encompass the holistic management of these patients from surgical management of the fracture to rehabilitation and prevention of subsequent fragility fractures. We have also included reports on several successful models of comanaged care and geriatric fracture programs, and several review articles on how these programs affect the outcome of patients with fragility hip fractures. We hope it will serve as a basis for better understanding of the orthopedic challenge in the management of such a major health problem.

Conflicts of Interest Dr. Leung is the speaker for Synthes and has received research support from Synthes; Dr. Blauth performs consultant and teaching activities with Synthes; Dr. Bavonratanavech declares no conflicts of interest.

Open Access This article is distributed under the terms of the Creative Commons Attribution Noncommercial License which permits any noncommercial use, distribution, and reproduction in any medium, provided the original author(s) and source are credited.

\section{References}

1. United Nations, Department of Economic and Social Affairs, Population Division (2007) World population prospects: the 2006 revision, highlights, working paper no. ESA/P/WP.202

2. Cooper C, Campion C, Melton LJIII (1992) Hip fractures in the elderly: a world-wide projection. Osteoporosis Int 2:285-289

3. Elliott J, Beringer T, Kee F, Marsh D, Willis C, Stevenson M (2003) Predicting survival after treatment for fracture of the proximal femur and the effect of delays to surgery. J Clin Epidemiol 56(8):788-795

4. Sernbo I, Johnell O (1993) Consequences of a hip fracture: a prospective study over 1 year. Osteoporosis Int 3:148-153

5. Schmidt AH, Leighton R, Parviz J, Sems A, Berry DJ (2009) Optimal arthroplasty for femoral neck fractures: is total hip arthroplasty the answer? J Orthop Trauma 23(6):428-433 
6. Adams CI, Robinson CM, Court-Brown CM, McQueen MM (2001) Prospective randomized controlled trial of an intramedullary nail versus dynamic screw and plate for intertrochanteric fractures of the femur. J Orthop Trauma 15(6):394400

7. Mereddy P, Kamath S, Ramakrishnan M, Malik H, Donnachie N (2009) The AO/ASIF proximal femoral nail antirotation (PFNA): a new design for the treatment of unstable proximal femoral fractures. Injury 40(4):428-432

8. Baumgaertner MR, Curtin SL, Lindskog DM, Keggi JM (1995) The value of the tip-apex distance in predicting failure of fixation of peritrochanteric fractures of the hip. J Bone Joint Surg Am 77 (7):1058-1064
9. Elder GM, Harvey EJ, Vaidya R, Guy P, Meek RN, Aebi M (2005) The effectiveness of orthopaedic trauma theatres in decreasing morbidity and mortality: a study of 701 displaced subcapital hip fractures in two trauma centres. Injury 36(9):1060-1066

10. Scottish Intercollegiate Guidelines Network (SIGN) (2009) Management of hip fracture in older people. A national clinical guideline. SIGN, Edinburgh, June 2009

11. British Orthopaedic Association Standards for Trauma (BOAST) (2007) Hip fracture in the older person. British Orthopaedic Association, September 2008

12. Leonard KL (2008) Is patient satisfaction sensitive to changes in the quality of care? An exploitation of the Hawthorne effect. J Health Econ 27(2):444-459 